\title{
La apuesta literaria del joven Bolaño: riesgo, desafío, vértigo, sin miopía
}

Soledad Bianchi ${ }^{1}$

Primera toma: primer plano $=$ Cuatro paltos de intrincados troncos y ramas, con miles y miles de hojas verdes rodean una mesa hexagonal, de madera. Y si miras a lo alto, verás que la cubren como un techo. Sentados a su rededor: Roberto Bolaño, Carolina López y el hijo de ambos, Lautaro (nacido en 1990), junto a Raquel Olea y a los dueños de casa: Guillermo Núñez y yo. Es noviembre de 1998; sábado, quizá; no hace demasiado calor y deben ser algo así como las dos de la tarde. Estamos almorzando, pero no recuerdo qué comimos. Tampoco, con precisión, de qué hablamos. No sé si el tiempo me hace equivocarme, pero más que una conversación colectiva con intercambio y superposición de opiniones y sonidos, me parece oír que se impone una voz segura, aunque sin entonación definida pues amalgama dejos del español de Chile, de México; uno más castizo, tal vez, y del catalán, sin duda: es el monólogo del invitado principal -con quien me encontraba por primera vez- que, entre cigarrillo y cigarrillo, armaba y transmitía entretenidas narraciones con sus propias vivencias, recientes y del pasado. Se diría que el humo le ayudaba a borrar límites entre sus realidades y las ajenas, y entre sus realidades y otras, menos reales, y que la demora en aspirarlo y expulsarlo le daba tiempo para evocar, pero, asimismo, para inventar.

A esa fecha, Roberto Bolaño ya comenzaba a ser conocido (por algo había sido invitado a Chile como Jurado del Concurso de Cuento de la revista Paula). A esa fecha, ya tenía una nutrida trayectoria literaria y había publicado unos seis o siete libros de poesía y narrativa: "Para Soledad y

Professora da Universidade do Chile. 
Guillermo, por una tarde agradabilísima. / Con un abrazo / Roberto / Stgo. Nov. 98", dice la Dedicatoria al volumen de cuentos, Llamadas Telefónicas, que nos traía de regalo. Era la segunda edición y acababa de aparecer, en Anagrama, hacía sólo un mes, en octubre de 1998, casi a un año de distancia de la inicial, de noviembre de 1997: con estos datos quiero indicar que ya publicaba en una Editorial importante -y hasta, muy importante-, y que sus escritos ya eran bien acogidos.

Venir a Chile como Jurado le significaba una vuelta de tuerca, y no dejaba de causarle risa porque -dijo- a poco de iniciar su estadía española, hacia 1977, para subsistir se había presentado, una y otra vez, a los innumerables Concursos Literarios, promovidos por Ayuntamientos y otras instituciones. Por lo general, además de dinero, los premiados eran publicados, y así lo (de)muestran varios volúmenes - de su poesía, incluso.

Nunca he olvidado, tampoco, el énfasis que puso Bolaño para explicar por qué, ahora, comenzaba a considerársele un escritor y a ser respetado. Con modestia (verdadera o falsa, y nos resultará imposible marcar la opción correcta), aclaró que mientras los españoles escribían bien, pero no tenían historias que relatar, a él no le faltaban asuntos para contar y ésa era su gran ventaja. (Mientras esto afirmaba, en noviembre de 1998, la novela que lo consagraría definitivamente: Los detectives salvajes, estaba en prensa o recién salida de ellas). No me acuerdo de mucho más, salvo que no nos preguntó nada sobre nuestros quehaceres: ni a Guillermo Núñez sobre su pintura ni a nosotras sobre nuestras clases universitarias ni nuestros intereses literarios.

A estas alturas, ustedes se estarán preguntando por qué Roberto Bolaño y su familia estaban almorzando en mi casa si no nos conocíamos. Resulta que hacía unos pocos días, cuando él acababa de llegar a Chile, desde Blanes, Barcelona, yo había respondido su "llamada telefónica" de saludo y habíamos quedado de encontrarnos... Resulta que, con Bolaño, nunca nos habíamos visto, pero nos conocíamos desde hacía mucho por una larga correspondencia que se había iniciado por 1979. Podría decirse que éramos "amigos epistolares" (así traduzco la expresión del inglés: "pen friend" o "pen pal", literalmente: amigo de pluma que, en el caso de Bolaño, debe extenderse al bolígrafo, la máquina de escribir y algo, al computador). Aquí, entonces, se abre el círculo... 
Estoy segura que hay otra interrogante en el aire... Al parecer, fui yo quien contactó a Bolaño. El 17 de agosto de 1979 está fechada la carta más antigua que encontré. En ella, yo le escribía para solicitarle colaboraciones - poemas, en especial - para Araucaria, una revista cultural del Partido Comunista, que aparecía en el exilio desde 1977, cuyo Consejo de Redacción yo integraba. Por mi parte, yo había leído escritos suyos y de Bruno Montané, en la revista cubana, Casa de las Américas, y así se lo manifiesto. Desde ese momento, establecimos un intercambio constante, aunque no siempre regular, que se fue distanciando e interrumpiendo con mi regreso a Chile, desde Francia, en 1987.

Segunda toma: hay cientos de papeles sobre una mesa, en mi escritorio. En cajas y cajones, cajitas y cajotas; bolsas, bolsitas y bolsones, busco correspondencia de Roberto Bolaño. Sé que tengo, pero no sé cuánta ni dónde está, precisamente.

Es muy posible que fuera más, pero cuando intenté recolectarla y ordenarla, encontré cerca de una cincuentena, entre cartas y tarjetas postales: con y sin sobres; dobladas y abiertas; en hojas blancas o lineadas o arrancadas de cuadernos, como con prisa, dejando el papel roto y de bordes irregulares; en ocasiones, con estrellitas separadoras de párrafos, como en algunos de sus cuentos o de sus poemas; manuscritas, la inmensa mayoría: con letra parejita y redondeada y en líneas muy rectas; a máquina, las menos; a veces, con notas al margen o con una y hasta con más de una PostData y como firma, casi nunca el nombre "Roberto" y el apellido, jamás; en cambio, escrita siempre a mano, una gran R final, acompañada de un punto.

Aunque hay muchas cartas que carecen de fechas, pienso que puede "armarse" un cierto... relato (Ilamémoslo así), una secuencia que responde a una cronología aproximada, basándose, en parte, en ciertas repeticiones: Bolaño era bastante obsesivo en sus preocupaciones e intereses, y hay asuntos sobre los que vuelve una y otra vez "a riesgo de ser majadero" (como él mismo dice). Es cierto, por lo demás, que en los contactos epistolares es necesario reiterar si se tiene en cuenta la tardanza que va de una carta a otra. Para esta ordenación ayudan, asimismo, sus menciones temporales en pinceladas sugerentes de ciertas 
variaciones: frío, tibieza, el paso de las estaciones, la extensión de los días, la presencia o ausencia de luz, el canto de ciertas aves, cómo mudan los árboles...

Pero más que saber cuánto ha llovido o si escasean los turistas o si son rubios o ruidosos, lo que (me) importaba, en la actualidad, al leer y re-leer esta correspondencia, era ir encontrando -y recogiendo- los rasgos del remitente para elaborar su "retrato", sea porque los explicitaba, sea porque podían deducirse, lateral o diagonalmente, de lo que el mismo Bolaño - persona y personaje- señalaba u omitía. Me preocupaba y me preguntaba si yo podría ver y decir algo diferente al mito-Bolaño ya tan instalado, sin plegarme a la leyenda ni instalar una nueva. Titubeaba, asimismo, si, en la lectura de las reflexiones de Bolaño, descubriría nuevos datos, actitudes, decires: antecedentes, detalles, notas, que no estuvieran en internet pues "google" (al que no teníamos acceso pues no existía, y no existió en buena parte de la etapa de nuestro correo) parece haberlo fagocitado todo en los cientos y cientos de páginas sobre los aspectos más disímiles de este escritor, quien -a su vez- todo lo fagocitaba... y no en "google", precisamente. Mas, es claro que su complejidad no la consiguen agotar ni esta suerte de enciclopedia "infinita" ni tampoco mi mirada. Y, a pesar de no referir a sí mismo, el complicado "retrato" a trazar y a obtener -como de soslayo-, se me figuró cercano a la descripción que Bolaño hace sobre cómo acceder al espacio donde él habita, en Barcelona: "... para llegar a mi casa hay que subir cuatro pisos, dar vueltas por un pasillo, cruzar un puente (sí, un puente que cuelga sobre un pequeño callejón empedrado), bajar diez escalones, torcer a la izquierda y allí está. Entre fantasmas de adolescentes catalanas." (carta no fechada: ¿julio de 1980?).

A partir de sus cartas, podría hacerse un listado muy extenso de sus ocupaciones y preocupaciones, propias y de su entorno; de menciones (cantantes, películas, actores y actrices, lecturas, músicos y música -con casi segura primacía del jazz-; escritores - de diversas nacionalidades y períodos, la Edad Media, inclusive-; deportistas, historias curiosas); de temas como la literatura chilena - que conoce bien - y sus autores, de su situación económica personal (asunto prioritario), de sus cotidianeidades (mudanzas de casas y de pueblos, alimentación), de sus amores, su gusto por los wargames, la estructura de sus obras, sus proyectos..., y yo podría seguir nombrando e indicando, indicando y nombrando. 
No obstante esa amplia variedad de preferencias hay una inquietud que está presente de carta en carta, sin obviarse nunca: se trata de una verdadera obstinación que lo desvela (literalmente) y es su porfía y pasión por la literatura y, en especial, por su propia escritura: el modo cómo la concibe y lo que está ideando y redactando. No es casualidad, entonces, que en cantidad de textos suyos, la literatura sea argumento fundamental o tema frecuente de conversación, y que muchos de sus personajes escriban. Bolaño se siente comprometido y ligado a un quehacer imposible de abandonar y ese compromiso lo enlaza y lo transforma en sinónimo de "riesgo", de "desafío", de "vértigo" (actitudes mencionadas en el título de este artículo). $Y$, en ocasiones, lo expresa en tono dramático (por los sacrificios que le exige) y, en otras, con humor, con mucho humor. Para esta suerte de pacto íntimo, este joven se exige -y exige a los otros - estos talantes que, de acuerdo a sus estrictas normativas y criterios, aproximan o separan de su noción de escritor, de su noción de literatura: “... yo no sentía ganas de viajar [hace 3 años, cuando salí de España] porque escribía mucho y eso ya era suficiente vértigo..." (carta del 24 de junio de 1985).

$Y$ de acuerdo al respeto o desacato de esas conductas hay pelambrillos (= chismes) simpáticos y comentarios inclementes sobre terceros; afirmaciones drásticas y enfáticas y serias, de las que, de inmediato, se contradice: "No creas nada" -me previene- y me deja estupefacta, sin saber qué pensar. Hay veces, también, que elabora y despliega narraciones de los asuntos más nimios, como preparando futuras novelas: "Queridísima Soledad, antes que nada gracias por el giro [de dinero] -me comenta, tal vez en 1984-; la pobre Berthe [refiere a Berthe Trépat, personaje de Rayuela, de Cortázar, y nombre de una de las tantas revistas que Bolaño creó y promovió] casi se ha puesto a llorar, le emociona que desde su ciudad natal intenten hacer más llevadero su exilio. Si usted supiera lo dura que es Barcelona, me ha dicho. Y también: exprésele mi agradecimiento a esa dama sudamericana. Así están las cosas. ...".

No hay carta (yo creo que no hay NINGUNA de sus cartas) donde no aluda al poema o relato o novela que está escribiendo o piensa escribir, y mirado desde nuestro presente, podemos comprobar que la gran mayoría de sus anuncios literarios fue redactado y, con el tiempo, hasta publicado. Bolaño no es de esos autores que al contar lo que se proponen literariamente, lo dan por realizado. Él quiere ser escritor y sabe que lo será "aunque -como grafica en carta de junio de 1984- deba dejar el pellejo". 
OTRA TOMA: como el correo no era tan rápido, es posible que Roberto me haya telefoneado (por lo demás, lo hizo en muy pocas oportunidades. Recuerden que, en esa época, hablar por teléfono no era barato). Me habría llamado para indicarme que pronto, desde España, llegaría a Francia un amigo suyo (de cuyo nombre no puedo acordarme), chileno, creo, al que le había dado mis señas. Yo vivía, entonces, en Bobigny, un pueblo de la "banlieu" parisina, una comuna de los alrededores próximos a la capital, en un departamento cuyas ventanas daban a la Avenida Salvador Allende (felizmente, la puerta de ese edificio, perteneciente al Municipio, estaba en otra calle -la rue du Chemin Vert = calle del Camino Verde - porque, de lo contrario, ijamás hubiera recibido cartas desde Chile!). Debe haber sido entre 1979 y 1981 porque este año, yo me mudé a vivir a Boësse, un pueblito de provincia, cercano a París (jnótese esta curiosidad!: B de Bolaño-Bianchi-Barcelona-Blanes-Bobigny-Boësse).

No era tan fácil llegar a Bobigny, donde, en esa época, no había metro, y eran pocos los amigos que nos visitaban y menos, sin avisar. Una tarde, estando ya oscuro, sonó el timbre. Extrañada, fui a abrir. Mayor fue mi extrañeza cuando dos policías (franceses, por supuesto) preguntaron por Madame Bianchi. ¡Imagínense a una Refugiada Política que lo único que quiere es pasar inadvertida, solicitada por la autoridad! Muy amablemente, los Agentes me consultaron si yo conocía a tal persona. Intenté explicarles, temerosa del lío en que podría haberse complicado el compatriota, y cuando me atreví a averiguar, comentaron que el joven se había suicidado en un bosque contiguo a la primera estación de trenes francesa, no tan lejos de la frontera española, y que en su libreta de direcciones aparecía mi nombre y mi domicilio. $Y$ todo llegó hasta aquí, reglamentariamente hablando. Ese desconocido, ese suicida, era... jel amigo de Bolaño!

Sin duda, conversamos, ambos, de este triste y misterioso asunto. $Y$ hoy, a la distancia, imagino esta toma como un posible tema y germen potencial de uno de sus relatos, de un cuento muy suyo, escrito por ese inagotable lector de novelas policiales que era /que fue Roberto Bolaño.

¿SE CIERRA UN CÍRCULO? : con posterioridad al almuerzo en nuestra casa, en noviembre de 1998, acompañé a Bolaño y su familia al hotel en que se hospedaban. Estaba en una calle pequeña, cerca de Apoquindo 
y del Stadio Italiano. Nos despedimos y quedamos de vernos dentro de dos o tres días cuando se presentaría su novela, La pista de hielo, en la Plaza Mulato Gil. Algo de esta junta relata en Entre Paréntesis (distinto es el relato de Pedro Lemebel, otro de los asistentes al encuentro). Después, no lo volví a ver.

Hace algo más de dos años, en enero del 2015, se concretó el traspaso (me cuesta decir: "negocio") de "mis" cartas de Roberto Bolaño a la Universidad Diego Portales. Ese miércoles fui invitada a almorzar con varias autoridades. En la tarde de ese mismo día, una amiga celebraba su cumpleaños 90 y yo estaba convidada. Cuando me iba acercando al lugar donde se realizaba el festejo, fui reconociendo que era el mismo hotel donde se había alojado Roberto Bolaño, y donde yo lo había ido a dejar, en 1998. ¿Casualidad? ¿Sincronía? ¿Se cerró un círculo o/y se abre otro y por él estamos aquí?

TRAVELLING: Voy en auto. Conduzco bordeando el largo muro que, por la Avenida Quilín, recorre y encierra la Viña Cousiño Macul. Para mí es un trayecto habitual y casi cotidiano. Es el 15 de julio del 2003. Debe ser una hora exacta porque la radio que oigo transmite noticias: una entre ellas: que Roberto Bolaño acaba de morir. El golpe me golpea y quiebra la monotonía de mi repetido recorrido. ¡Y yo ni siquiera sabía que estaba enfermo!

¿Dónde se esfumó nuestra amistad? ¿Cuándo se hizo humo ese diálogo que nos acercaba en la distancia?: ¿fue el internet?, ¿fue su necesidad de dedicarse en exclusiva a la literatura, a la escritura?, ¿fue el reconocimiento y la notoriedad que lo cambió o lo obligó a cambiar?, ¿fueron los elogios?, ¿serían los aduladores?, ¿fue mi estadía en Chile y mis obligaciones "chilenas" que me hicieron silenciarme?, ¿fueron mis viajes?, ¿fue su enfermedad? Fuera lo que fuera, con la noticia viva en los oídos, medio aturdida por la pena, con dolor, al saber que Roberto Bolaño ya no vivía, entendí que el joven Bolaño que yo "conocí" también había muerto pues no existía hacía mucho. No obstante, aún puedo -y podemos- encontrarlo en las cartas que me envió cuando él mismo se juzgaba un "aprendiz de escritor". 